\title{
Diseño de un Modelo de Gestión de Riesgos basado en ISO 31.000:2012 para los Procesos de Docencia de Pregrado en una Universidad Chilena
}

\author{
Yolanda E. Gutiérrez y Aurora Sánchez-Ortiz \\ Facultad de Economía y Administración, Dpto. de Administración, Univ. Católica del Norte, \\ Av. Angamos 0610, Antofagasta-Chile. (e-mail: ygutierrez@ucn.cl; asanchez@ucn.cl)
}

Recibido Ago. 11, 2017; Aceptado Oct. 11, 2017; Versión final Ene. 23, 2018, Publicado Ago. 2018

\begin{abstract}
Resumen
Este estudio propone un modelo de gestión de riesgos, basado en la norma ISO 31000:2012 para el área de docencia de pregrado. La gestión integral del riesgo es un componente estratégico esencial que permite establecer los puntos de control para evitar incumplimientos de los objetivos de la organización. El modelo propuesto permite apoyar los procesos de acreditación a través de indicadores orientados a mejorar la eficiencia de los procesos docentes. Para esto, el modelo genera matrices de riesgo y establece Indicadores Claves de Riesgo (KRI). La aplicación del modelo se realiza en la Universidad Católica del Norte (UCN) en Chile, la cual cuenta con sedes en Antofagasta y Coquimbo en las que se imparten 35 carreras. Los resultados obtenidos permitieron definir riesgos inherentes y residuales en los procesos docentes y el establecimiento de controles sobre los procesos críticos.
\end{abstract}

Palabras clave: gestión de riesgos; docencia de pregrado; matrices de riesgos; ISO 31.000; KRI

\section{Design of a Risk Management Model based on ISO 31.000:2012 for Undergraduate Teaching Processes in a Chilean University}

\begin{abstract}
This study proposes a risk management model, based on the ISO 31000 standard for undergraduate teaching. Comprehensive risk management is an essential strategic component that allows the establishment of control points to avoid non-fulfillment of the organization's objectives. The proposed model allows supporting accreditation processes through parameters oriented to improve the efficiency of teaching processes. For this, the model generates matrixes and define Key Risk Indicators (KRI). The application of the model is done at Universidad Católica del Norte in Chile (UCN), which has branches in Antofagasta and Coquimbo which offer 35 university careers. The results obtained allowed the definition of inherent and residual risks in the teaching processes and the establishment of controls on the critical processes.
\end{abstract}

Keywords: Risk management; undergraduate teaching; risk matrices; ISO 31,000; KRI 


\section{INTRODUCCIÓN}

Las organizaciones enfrentan permanentemente influencias internas y de su entorno las que podrían afectar la ejecución de su planificación estratégica. Estas influencias a menudo son consideradas riesgos. Aunque la mayoría de los autores reconocen su importancia, no existe consenso en la literatura respecto a la mejor definición del término riesgo. Aven (2012) sostiene que el término "Riesgo" está sujeto a múltiples interpretaciones ya que algunas de sus definiciones se basan en la probabilidad, el azar o los valores esperados, otras sobre eventos o peligros indeseables y otros sobre incertidumbres. Luko (2013) agrega que para una mejor comprensión del riesgo se requiere el entendimiento del grado en el cual un resultado se puede apartar del objetivo y por tanto esto requiere el conocimiento de lo que puede suceder, cuan a menudo y con qué consecuencias. Cassidy et al., (2001) definen el riesgo como cualquier problema que impacta la capacidad de una organización para alcanzar sus objetivos e identifican cinco tipos del riesgo : a) el riesgo estratégico, que afecta la capacidad de una organización para alcanzar sus objetivos, b) el riesgo financiero, es el riesgo que puede resultar en una pérdida de activos, c) el riesgo operativo, es el riesgo que afecta a un proceso de gestión en marcha, d) el riesgo de cumplimiento, es el riesgo que afecta el cumplimiento de las leyes externamente impuestas y regulaciones así como con políticas y procedimientos internos impuestos relacionados con seguridad, conflicto de intereses y otros, e) el riesgo de reputación, es el riesgo que afecta la reputación, la marca o ambas.

La necesidad de las organizaciones de controlar los riesgos de una manera sistemática y completa ha dado origen a la gestión de riesgos y las normas inherentes a este propósito (Luko, 2012; Lalonde y Boiral, 2012). Hope y Player (2012) plantean que la mayor parte de las amenazas rara vez se miden o controlan, siendo entonces necesario gestionar los riesgos a través de un sistema. Cassidy et al (2001) propusieron la necesidad de una estrategia para gestionar de forma más eficiente el riesgo en la educación superior con el objetivo de hacer frente a un entorno cada vez más dinámico. Ellos sostienen que hay mucho que ganar agregando una nueva vista, una que apunte a administrar el lado positivo del riesgo y para ver las muchas oportunidades que presenta con una visión equilibrada del riesgo minimizando los peligros, influyendo y controlando las incertidumbres, y gestionando las oportunidades.

La gestión de los riesgos es un tema que sin duda impacta la calidad de las Instituciones de educación superior y por tanto una importante preocupación para las organizaciones que se enfrentan a procesos de evaluación de calidad. Esta evaluación es aún un desafío para muchos países y existen diversos estudios a nivel internacional que lo corroboran. Larrán et al., (2016) midieron la sostenibilidad en las universidades españolas y destacan las debilidades de las herramientas existentes para evaluar el desempeño de las instituciones de educación superior hacia la sostenibilidad proponiendo la necesidad de incorporar en forma integrada las dimensiones sociales, económicas y ambientales de la sostenibilidad en las universidades. Lumino et al., (2017) analizan los grandes cambios que se han producido en la evaluación de las universidades italianas destacando el complejo conjunto de formas de conocimiento, medios técnicos y temas colectivos e individuales identificando algunos de los riesgos paradójicos de la evaluación, como son la contractualización, despolitización y fabricación. Lundquist (2015) destaca la variedad, el tipo y el volumen de riesgos que afectan las instituciones de educación superior y el rol de las agencias de acreditación en evaluar que estas instituciones demuestren una eficaz planificación integrada a la toma de decisiones, incluyendo la utilización de la información obtenida de la gestión integral de riesgos como parte del proceso de gobierno y gestión.

En Chile, el modelo de calidad de la Educación Superior más utilizado es el de acreditación de la Comisión Nacional de Acreditación (CNA). Espinoza, y González (2013) destacan como características centrales que distinguen a este sistema de evaluación de calidad de Instituciones de educación superior en Chile las siguientes : a) el respeto por la autonomía institucional; b) la base voluntaria del sistema, con la excepción de las carreras médicas y docentes porque estas áreas se han definido como prioridades para el desarrollo del país por parte del gobierno chileno -; c) la autoevaluación y la revisión por pares como características clave de la calidad de la evaluación; d) la participación de agencias públicas y privadas; e) el énfasis en la autorregulación; y el acceso a la información por parte de usuarios e instituciones para la toma de decisiones. Este sistema ha impulsado a las instituciones de educación superior a incorporarse a él buscando demostrar su competitividad, grado de aseguramiento de la calidad en el funcionamiento de la institución y finalmente una vez acreditadas acceder a financiamiento tanto institucional como estudiantil.

No obstante, los procesos de acreditación no miden explícitamente el riesgo inherente al negocio que podría afectar al conjunto de políticas y mecanismos institucionales destinados a asegurar la calidad de la formación conducente a un título, es decir, a la Docencia de Pregrado. Brewer y Walker (2011) destacan que las instituciones de educación superior reconocen cada vez más que la gestión efectiva del riesgo es importante para ellos pero estas instituciones se han centrado fundamentalmente en prevenir el riesgo de la eventualidad y la gestión de los riesgos después del evento. Sin embargo son muy pocas las instituciones que han implementado el riesgo en un enfoque integrado a marco de planificación estratégica o de aseguramiento de la calidad. Estos autores proponen que un marco de análisis efectivo de la administración de riesgos debe 
vincular el gobierno institucional, la gestión de riesgos y los objetivos estratégicos de una universidad. La experiencia internacional también destaca esta gran falencia. Mitroff et al., (2006) sostienen que en los Estados Unidos el nivel de preparación de Universidades para enfrentar grandes crisis es aun complejo y que uno de los problemas es que aunque la misión central de estas instituciones es la educación, las universidades ofrecen una multiplicidad de servicios y que muchas de ellas son similares a empresas complicadas con millones de dólares en juego, como el caso de la Universidad de Yale. Lundquist (2015) en este mismo sentido destaca la variedad, el tipo y el volumen de riesgos que afectan las instituciones de educación superior en los Estados Unidos y el rol de las agencias de acreditación en evaluar que estas instituciones demuestren una eficaz planificación integrada a la toma de decisiones, incluyendo la utilización de la información obtenida de la gestión integral de riesgos como parte del proceso de gobierno y gestión. Gustafson (2017) en Suecia analizó el proceso de gestión del riesgo de seguridad en universidades e institutos universitarios destacando que para enfrentar los desafíos de la educación superior de hoy el enfoque debe estar en más relaciones interpersonales en cuestiones de seguridad que en equipos técnicamente avanzados. Mukhtarova y Smith (2014) también destacan el rol de la cultura organizacional y la gestión de proyectos en los problemas que ha presentado el progreso de la implementación de proyectos en la educación superior en Kazakhstan con miras a alcanzar estándares internacionales e integrarse al ámbito educativo mundial.

Entendiendo la importancia de los riesgos, se han creado normas de calidad específicas que incorporan la gestión de éstos, siendo una de ellas la norma ISO 31.000. Esta norma ISO permite establecer principios de gestión de riesgos y determinar el impacto que éstos pueden generar en la consecución de los objetivos estratégicos de una organización. Esta norma define riesgos como "efecto de la incertidumbre sobre el cumplimiento de los objetivos" (Instituto Nacional de Normalización, 2012). Olechowski et al., (2016) analizaron el poder de los once principios de gestión de riesgos en la norma ISO 31000 para explicar los resultados positivos de los proyectos -lograr de mejor manera los costos, el cronograma, los objetivos técnicos y de clientes, además de lograr una ejecución de proyecto más estable - evidenciando la existencia de un vínculo entre la gestión del riesgo de calidad y los proyectos exitosos. Se ha demostrado que el proceso de promoción del mejoramiento de la calidad y la integración acelera el desarrollo integral de los diversos países de Latinoamérica y es una estrategia que permite diseñar respuestas conjuntas, comunes y coordinadas a los desafíos de la globalización en el campo de la educación superior (Tünnermann, 2008). Galarza y Almuiñas (2015) destacan que la gestión de riesgos aplicada al proceso de planificación estratégica en instituciones de educación superior disminuye las vulnerabilidades, incrementa la resiliencia y aporta beneficios que se reflejan en la calidad del proceso y en sus resultados e impactos.

Tlapa et al., (2009), por otra parte, sostienen que las Instituciones de Educación Superior deben ser un ejemplo para la sociedad en que se encuentran por lo cual el utilizar sistemas bajo las normas ISO para gestionar la calidad en los procesos claves, estratégicos y de apoyo es fundamental. Es también una estrategia apropiada para diseñar respuestas conjuntas, comunes y coordinadas a los desafíos que plantea el actual proceso de globalización en el campo de la educación superior. Por estas razones la definición de riesgo utilizada en este estudio es la propuesta en por la norma ISO 31.000

Este estudio plantea la interrogante de ¿Cuáles son las áreas de la Docencia de Pregrado más impactadas por los riesgos? Este análisis utiliza el método de investigación-acción. Gallego, Muñoz y Carmona (2008) señalan que este método es una forma colaborativa de investigar que busca unir teoría y práctica, es decir, que presenta una doble finalidad: generar un beneficio al "cliente de la investigación" y, al mismo tiempo, generar "conocimiento de investigación" relevante. Primero se plantea la fundamentación teórica del modelo, para luego analizar su aplicación en una universidad chilena.

\section{GESTIÓN INTEGRAL DEL RIESGO}

Las normas ISO tienen una amplia aceptación en los organismos gubernamentales en Chile, por lo que se decide utilizar como parte del marco teórico para el análisis del presente trabajo. "La norma ISO 31000 define la gestión del riesgo como el conjunto coordinado de actividades que se desarrollan en una organización en referencia al tema del riesgo. Del proceso de gestión del riesgo indica que es la aplicación sistemática de políticas, procedimientos y prácticas a las actividades de comunicar, consultar, establecer el contexto, identificar, analizar, evaluar, tratar, monitorear y revisar los riesgos" (Hurtado, 2011). No obstante, no tiene como objetivo promover la uniformidad en la gestión del riesgo a través de las distintas organizaciones, debido a que el diseño y la implementación de planes y marcos de trabajo necesita tener en cuenta las necesidades de una organización específica, sus objetivos, su contexto, estructura, operaciones, procesos, etc.

La "Gestión Integral del Riesgo" tiene por objetivo identificar y gestionar los riesgos del negocio (o corporativos), teniendo un carácter estratégico. Para ello, está compuesta por un conjunto de técnicas y herramientas que apoyan la toma de decisiones, a partir del análisis de la incertidumbre y la posibilidad de ocurrencia de ciertos eventos o riesgos. Los principios básicos para la gestión del riesgo son añadir o crear 
valor, contribuir a la consecución de los objetivos, estar integrada en los procesos de una organización, ser parte del sistema de gestión integral de la organización, servir a la toma de decisiones, tratar la incertidumbre, basarse en la mejor información disponible, estar hecha a la medida, considerar los factores humanos y culturales, y facilitar la mejora continua de la organización.

ISOTools (2015) explica que como primera etapa se debe establecer "qué se busca con la implementación del sistema de gestión de riesgos" definiendo su alcance, para luego establecer responsables en la ejecución del proyecto de gestión de riesgos. Para cada proceso se realiza la evaluación de riesgos y éstos se priorizan de acuerdo al impacto que tengan tanto en la unidad de origen como en la organización en su conjunto, con ello se establecen acciones de control. "La evaluación del riesgo se puede realizar con diferentes grados de profundidad y de detalle, y utilizando uno o varios métodos que varían desde simples a complejos. La forma de la evaluación y de sus resultados debe ser consecuente con los criterios de riesgo desarrollados como parte del establecimiento del contexto" (INN, 2013).

Los tipos de técnicas de evaluación de riesgos se pueden clasificar de acuerdo a la etapa del proceso en que se utilicen, en técnicas de identificación del riesgo, de análisis del riesgo (consecuencia, probabilidad y nivel del riesgo) o de valoración del riesgo. La matriz de riesgos o consecuencia/probabilidad es una de las herramientas más utilizadas para la evaluación de riesgos por su fácil aplicabilidad, es un instrumento dinámico que permite documentar, analizar y hacer seguimiento a los riesgos a partir de la evaluación de su probabilidad e impacto. Albanese (2012) define la matriz de riesgo como una herramienta que permite disminuir la subjetividad de la evaluación de riesgos, a partir de su cuantificación en base a parámetros y valores previamente asignados. "La matriz de consecuencias/probabilidad es un medio de combinar clasificaciones cualitativas o semicualitativas de consecuencia y probabilidad para producir un nivel de riesgo o una clasificación de riesgos" (INN, 2013).

La construcción de esta herramienta de control de gestión considera la identificación de riesgos a partir de los objetivos estratégicos de la organización, para luego determinar la probabilidad de que el riesgo ocurra y los posibles efectos sobre la organización. En función de la ubicación de los riesgos en la matriz es posible definir acciones a realizar, las opciones de tratamiento del riesgo no se excluyen necesariamente unas de otras, ni son apropiadas en todas las circunstancias, éstas pueden incluir: evitar el riesgo decidiendo no iniciar o continuar con la actividad que causa el riesgo, aceptar o aumentar el riesgo a fin de perseguir una oportunidad, eliminar la fuente del riesgo, modificar la probabilidad, modificar las consecuencias, compartir el riesgo con otras partes (incluyendo los contratos y la financiación del riesgo), retener el riesgo en base a una decisión informada (Instituto Nacional de Normalización, 2012). Las fortalezas de esta técnica están dadas por su facilidad de uso y porque proporciona una rápida jerarquización de los riesgos. No obstante, se debe definir cuidadosamente la escala de medición para que no resulte ambigua y se deben buscar criterios de clasificación que eviten la subjetividad de los evaluadores.

Otra herramienta que contribuye a la toma de decisiones corresponde a los indicadores claves de riesgos o KRI por sus siglas en inglés (Key Risk Indicator). Delfiner y Pailhé (2008) indican que los KRI son herramientas para estimar la probabilidad y severidad de eventos, pudiendo ser de carácter cualitativo o cuantitativo y expresarse en porcentajes, cantidades o montos de dinero. Además, señalan ciertos atributos deseables en los KRI como que permitan medir y controlar un riesgo, permitan actividades preventivas para minimizar pérdidas, y permitan detectar tendencias y cambios en los niveles de riesgos. Los conceptos de riesgos son aplicables en cualquier tipo de organizaciones, incluidas las de Educación Superior. La Comisión Nacional de Acreditación (CNA) en Chile se enmarca dentro de la Ley de Aseguramiento de la Calidad de la Educación Superior $\mathrm{N}^{\circ} 20.129$, ésta ha definido la acreditación institucional como un proceso voluntario para las instituciones de educación superior "cuyo objeto es evaluar el cumplimiento de su proyecto corporativo y verificar la existencia de mecanismos eficaces de autorregulación y de aseguramiento de la calidad, así como propender al fortalecimiento de su capacidad de autorregulación y al mejoramiento continuo". Siendo relevante en este contexto el estudio de los riesgos que ayuden a fortalecer el sistema.

\section{DOCENCIA DE PREGRADO EN LA UCN}

LA CNA evalúa la docencia de pregrado entendiéndola como "el conjunto de políticas y mecanismos institucionales destinados a asegurar la calidad de la formación conducente a un título" (Comisión Nacional de Acreditación, 2013). Para ello la CNA ha definido la evaluación de cinco procesos, estipulados en el Reglamento sobre las áreas de acreditación acorde al artículo $17^{\circ}$ de la ley 20.129 , en su versión 2013 . Éstos son: (i) diseño y provisión de carreras y programas en todas las sedes de la institución, (ii) proceso de enseñanza, (iii) dotación académica/docente, (iv) estudiantes, y (v) utilización de los procesos o resultados de la investigación para mejorar la calidad de la docencia impartida, los cuales a su vez se dividen en subprocesos establecidos en la Tabla 1. 
En el área Docencia de Pregrado, la universidad ha definido un conjunto de objetivos estratégicos para el periodo 2015 - 2019, en su Plan de Desarrollo Corporativo (PDC). Con el propósito de identificar los principales riesgos que podrían impactar el logro de estos objetivos se analiza la correspondencia con los subprocesos de la Docencia de Pregrado, detectando aquellos que son claves por la cantidad de objetivos con que se relacionan (Tabla 1).

Tabla 1: Correspondencia objetivos PDC y Procesos Docencia de Pregrado UCN para definición de sub-procesos críticos

\begin{tabular}{|c|c|c|c|c|c|c|c|}
\hline $\begin{array}{l}\text { Proceso } \\
\text { CNA }\end{array}$ & $\begin{array}{l}\text { Sub-Proceso/ } \\
\text { Objetivo PDC }\end{array}$ & $\begin{array}{c}\text { Desplegar } \\
\text { el Proyecto } \\
\text { Educativo } \\
\text { en todo el } \\
\text { quehacer } \\
\text { docente }\end{array}$ & $\begin{array}{c}\text { Mejorar el } \\
\text { desempeño } \\
\text { de carreras y } \\
\text { programas }\end{array}$ & $\begin{array}{c}\text { Fortalecer } \\
\text { las } \\
\text { capacidad } \\
\text { es } \\
\text { docentes } \\
\text { de la } \\
\text { planta } \\
\text { oficial, } \\
\text { especial y } \\
\text { prof.. hora }\end{array}$ & $\begin{array}{c}\text { Asegurar } \\
\text { la calidad } \\
\text { de la } \\
\text { formación } \\
\text { de } \\
\text { pregrado }\end{array}$ & $\begin{array}{c}\text { Mejorar el } \\
\text { desempeño } \\
\text { docente de los } \\
\text { departamentos } \\
\text { y escuelas }\end{array}$ & $\begin{array}{l}\text { Número } \\
\text { de } \\
\text { objetivos } \\
\text { a los que } \\
\text { impacta }\end{array}$ \\
\hline \multirow{4}{*}{$\begin{array}{l}\text { Diseño y } \\
\text { provisión de } \\
\text { carreras y } \\
\text { programas }\end{array}$} & $\begin{array}{l}\text { Oferta de } \\
\text { carreras }\end{array}$ & & & & * & & 1 \\
\hline & $\begin{array}{l}\text { Diseño } \\
\text { curricular }\end{array}$ & * & * & & & & 2 \\
\hline & $\begin{array}{l}\text { Asignación de } \\
\text { recursos para } \\
\text { la docencia }\end{array}$ & & * & * & * & & 3 \\
\hline & $\begin{array}{l}\text { Acreditación } \\
\text { de carreras de } \\
\text { pregrado }\end{array}$ & & * & & * & & 2 \\
\hline \multirow{2}{*}{$\begin{array}{l}\text { Proceso de } \\
\text { enseñanza }\end{array}$} & $\begin{array}{l}\text { Selección y } \\
\text { admisión }\end{array}$ & & & & & & 0 \\
\hline & $\begin{array}{l}\text { Proceso de } \\
\text { enseñanza/ } \\
\text { aprendizaje }\end{array}$ & * & * & * & & & 3 \\
\hline $\begin{array}{l}\text { Dotación } \\
\text { académica/ } \\
\text { docente }\end{array}$ & $\begin{array}{l}\text { Dotación } \\
\text { académica/ } \\
\text { docente }\end{array}$ & & * & * & & * & 3 \\
\hline \multirow{4}{*}{ Estudiantes } & $\begin{array}{l}\text { Servicios de } \\
\text { ayuda } \\
\text { estudiantil }\end{array}$ & & & & * & & 1 \\
\hline & $\begin{array}{l}\text { Seguimiento } \\
\text { de ex } \\
\text { estudiantes }\end{array}$ & & * & & * & * & 3 \\
\hline & $\begin{array}{l}\text { Progresión de } \\
\text { los estudiantes }\end{array}$ & & * & & * & * & 3 \\
\hline & $\begin{array}{l}\text { Política } \\
\text { arancelaria }\end{array}$ & & & & & & 0 \\
\hline $\begin{array}{l}\text { Utilización } \\
\text { de los } \\
\text { procesos o } \\
\text { resultados } \\
\text { de la } \\
\text { investigación } \\
\text { para mejorar } \\
\text { la calidad de } \\
\text { la docencia } \\
\text { impartida }\end{array}$ & $\begin{array}{l}\text { Utilización de } \\
\text { los procesos o } \\
\text { resultados de } \\
\text { la } \\
\text { investigación } \\
\text { para mejorar } \\
\text { la calidad de la } \\
\text { docencia } \\
\text { impartida }\end{array}$ & & * & & * & * & 3 \\
\hline
\end{tabular}

Como se observa en la Tabla 1, se identifica que los sub-procesos claves corresponden a Asignación de Recursos para la Docencia, Proceso de Enseñanza/Aprendizaje, Dotación Académica Docente, Seguimiento de Ex Estudiantes, Progresión de Estudiantes, Utilización de los procesos o resultados para mejorar la calidad de la docencia impartida. En adelante la evaluación de riesgos se enfoca sólo en estos sub-procesos. Debido 
a que la medición de riesgos permite identificar cómo se ve expuesto el incumplimiento de los objetivos de los procesos, éstos se han definido de la siguiente manera:

El objetivo del sub-proceso de asignación de recursos para la docencia es generar sistemáticamente las condiciones idóneas para el desarrollo del proceso de enseñanza-aprendizaje. En el caso del sub-proceso de enseñanza/aprendizaje se busca asegurar la calidad del proceso de enseñanza-aprendizaje gestionando las estrategias pedagógicas, los procedimientos de evaluación del aprendizaje y de la docencia, el uso de las tecnologías y el seguimiento de los resultados. Para ello el sub-proceso de dotación académica/docente pretende disponer de personal académico que permita la consecución de los objetivos institucionales. Por otra parte, el seguimiento de ex estudiantes busca fortalecer el vínculo de los egresados con la institución, a la vez que se estudia su situación actual y se retroalimenta el proceso educativo y la oferta formativa. Mientras que la progresión de los estudiantes busca garantizar una formación adecuada del estudiante desde que ingresa a la Institución hasta que se inserta en el mundo laboral.

En cuanto a la utilización de los procesos o resultados de la investigación para mejorar la calidad de la docencia impartida, se quiere postular y adjudicar proyectos de investigación con fondos externos, integrando los resultados del trabajo investigativo a los procesos formativos del pregrado. Las fortalezas y debilidades de la Docencia de Pregrado en la UCN permiten comprender en mayor detalle el contexto de la organización. En la autoevaluación institucional con fines de acreditación y en la elaboración del plan de desarrollo corporativo se propone un análisis de estos elementos, los cuales fueron validados al momento de la evaluación de riesgos con los dueños de los procesos y sub-procesos para ver si aún persistían y si había otros elementos que considerar (ver Tabla 2).

Tabla 2: Análisis FODA Docencia de Pregrado UCN

\section{Fortalezas}

1) Alta tasa de ocupación de las vacantes UCN; 2) Alta empleabilidad al primer año de egreso, 3) Coordinación académica para carreras ofrecidas en la Casa Central y la Sede Coquimbo; 4) Programas de acompañamiento que permiten aumentar tasas de retención y disminuir tiempo de titulación; 5) Acompañamiento sistemático a la formación integral y al bienestar de los estudiantes de la UCN; 6) Posicionamiento a nivel nacional como una universidad inclusiva

\section{Debilidades}

1) Falta profundizar la evaluación y el seguimiento de la implementación de los rediseños curriculares; 2) Se deben mejorar los años promedio de acreditación de pregrado; 3) Se debe aumentar la vinculación con el medio (contacto con empresas); 4) No existe un mecanismo que asegure que el perfeccionamiento de la planta académica impacta positivamente a la docencia de pregrado; 5) Falta vincular la investigación con la docencia (trabajo con estudiantes).

\section{Oportunidades}

1) Adjudicación de proyectos externos que permiten fortalecer el pregrado y las innovaciones curriculares (ej. PMI); 2) Mayor movilidad y calidad en la formación de pregrado gracias a la implementación del sistema SCT; 3 ) Generación de clúster y asociaciones de vinculación con empresas de la zona.

\section{PROPUESTA DE UN MODELO DE GESTIÓN DE RIESGOS: METODOLOGÍA}

El modelo propuesto se basa en los principios de gestión de riesgos definidos en la norma ISO 31.000 y su estructura de construcción se detalla en la Figura 1. Los insumos estratégicos de la universidad y las herramientas de la norma, permiten generar un modelo de gestión que establezca los riesgos inherentes (propios de los procesos), los controles existentes y los riesgos residuales (actuales), con el fin de generar nuevas medidas de control sobre estos procesos. Para ello lo primero es establecer las definiciones que permiten su funcionamiento, tales como niveles de amenazas, vulnerabilidad y de riesgos. Las amenazas se van a entender como la probabilidad de que un evento ocurra con cierta magnitud e impida el cumplimiento de los objetivos de los procesos, contando con los niveles de improbable, remoto, posible, probable y frecuente (ver Tabla 3). Estos niveles se generan en función de la periodicidad con que podría ocurrir el evento, por ejemplo, si es posible que ocurra una vez en el año, tendrá un 8,33\% de probabilidad de ocurrencia (un evento dividido en los doce meses del año), mientras que si es posible que ocurra una vez en dos años tendrá un 4,17\% de probabilidad de ocurrencia (un evento dividido en los 24 meses del periodo). 


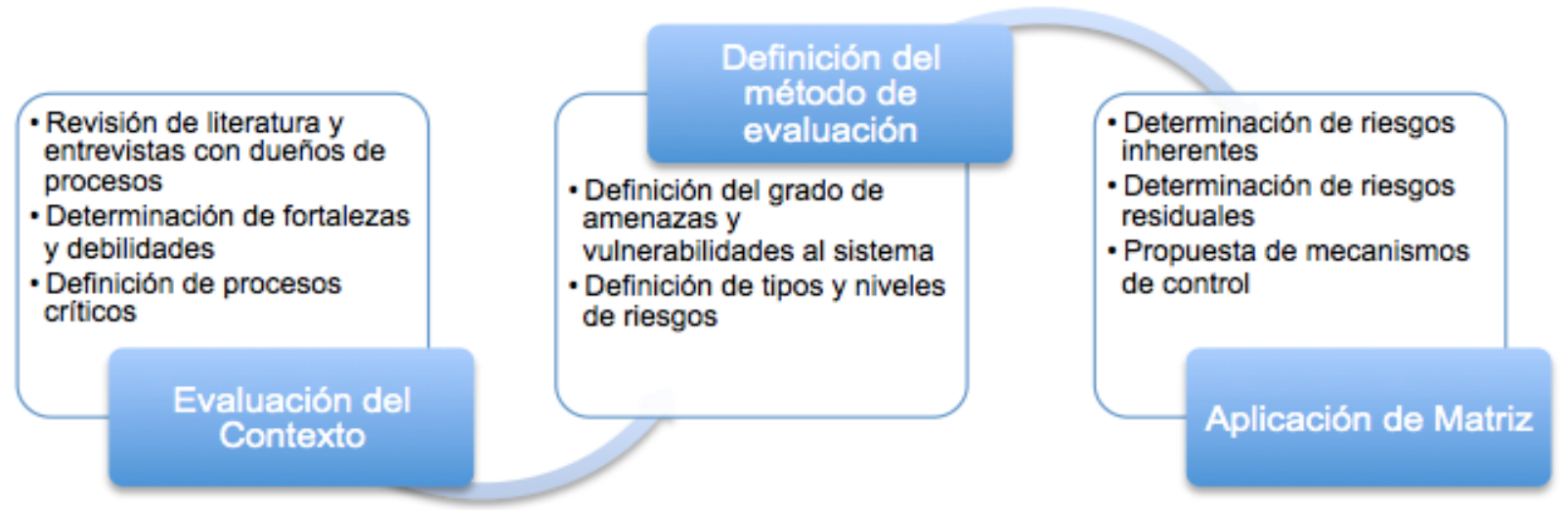

Fig. 1: Etapas de construcción del modelo de gestión de riesgos

Tabla 3: Niveles de amenaza definidos para la confección de la Matriz de Riegos

\begin{tabular}{|c|l|l|c|c|c|}
\hline Valor & \multicolumn{1}{|c|}{ Descripción } & \multicolumn{1}{|c|}{ Clasificación } & \multicolumn{2}{c|}{ Casos/Año } \\
\hline 1 & $\begin{array}{l}\text { Muy difícil que ocurra. Se espera que ocurra un caso entre 2 } \\
\text { y } 5 \text { años. }\end{array}$ & Improbable & $4,17 \%$ & Menor de \\
\hline 2 & $\begin{array}{l}\text { Limitada posibilidad de ocurrir, se espera que ocurra un caso } \\
\text { entre 1 y 2 años. Sucede de forma esporádica. }\end{array}$ & Remoto & $4,17 \%$ & $8,33 \%$ & Entre \\
\hline 3 & $\begin{array}{l}\text { Mediana posibilidad de ocurrencia, se espera que ocurra entre } \\
1 \text { y 3 eventos en 12 meses. Sucede algunas veces }\end{array}$ & Posible & $8,33 \%$ & $25,00 \%$ & Entre \\
\hline 4 & $\begin{array}{l}\text { Significativa posibilidad de ocurrencia, se espera que ocurran } \\
\text { entre 3 y 6 eventos en 12 meses. Sucede de forma reiterada }\end{array}$ & Probable & $25,00 \%$ & $50,00 \%$ & Entre \\
\hline 5 & $\begin{array}{l}\text { Alta posibilidad de ocurrencia, se espera que ocurran más de } \\
6 \text { eventos en 12 meses. Sucede de forma seguida. }\end{array}$ & Frecuente & $50,00 \%$ & Mayor de \\
\hline
\end{tabular}

Se decide considerar estos niveles dejando el periodo máximo de ocurrencia de un caso en 5 años, de acuerdo al tiempo que ha definido la institución para la ejecución de su Plan de Desarrollo Corporativo, es decir, en el menor nivel (improbable), un proceso de pregrado se podría ver afectado alguna vez durante el periodo 2015 - 2019, mientras que en el mayor nivel (frecuente) un proceso se podría ver afectado hasta 6 veces en un año. Acorde al marco conceptual de la gestión de riesgos estos niveles fueron acordados con el Director General de Pregrado de la UCN, bajo su calidad de autoridad en el área. La vulnerabilidad representa el efecto o impacto que podría tener la amenaza sobre los procesos de docencia de pregrado de la UCN, pudiendo clasificarse en insignificante, menor, moderado, mayor o crítico de acuerdo a cuánto afecte el cumplimiento del objetivo del proceso (ver Tabla 4).

Tabla 4: Niveles de vulnerabilidad definidos para la confección de la Matriz de Riesgos

\begin{tabular}{|c|l|c|}
\hline Valor & \multicolumn{1}{|c|}{ Descripción } & Clasificación \\
\hline 1 & $\begin{array}{l}\text { Las consecuencias no afectan de forma ninguna el cumplimiento del objetivo del } \\
\text { proceso. Los daños son muy pequeños. }\end{array}$ & INSIGNIFICANTE \\
\hline 2 & $\begin{array}{l}\text { Las consecuencias no afectan de forma significante el cumplimiento del objetivo del } \\
\text { proceso. Representan pérdidas o daños pequeños }\end{array}$ & MENOR \\
\hline 3 & $\begin{array}{l}\text { Las consecuencias solo afectan parcialmente la ejecución del proceso, pero ponen en } \\
\text { peligro su estabilidad. Pérdidas o daños moderados }\end{array}$ & MODERADO \\
\hline 4 & $\begin{array}{l}\text { Las consecuencias afectan de manera total la ejecución del proceso. Pérdidas o daños } \\
\text { significativos }\end{array}$ & $\begin{array}{l}\text { MAYOR } \\
\text { irrecuperables. Pérdidas o daños considerables }\end{array}$ \\
\hline 5 &
\end{tabular}

En base al cruce de los niveles de amenaza y de vulnerabilidad es posible definir el valor de un riesgo como la multiplicación de los anteriores, dividida por el valor máximo posible de la multiplicación. Por ejemplo, un riesgo con un nivel de amenaza 2 y vulnerabilidad 3, tendrá una probabilidad de ocurrencia de un $24 \%$, de acuerdo a la operación matemática $(2 \times 3) / 25$, y dado su impacto en el cumplimiento de los objetivos de los procesos se clasifica con un riesgo nivel 3 (ver Tabla 5). 
Tabla 5: Niveles de riesgos definidos para la clasificación de los eventos en la Matriz de Riesgos

\begin{tabular}{|c|l|c|c|}
\hline VALOR & \multicolumn{1}{|c|}{ DESCRIPCIÓN } & CLASIFICACIÓN & ACCIÓN \\
\hline 1 & $\begin{array}{l}\text { No se prevén daños y de presentarse son de baja cuantía. La probabilidad } \\
\text { de ocurrencia está entre un 0\% y un } 4,17 \% \text {, por lo que no se requiere } \\
\text { planificar acciones específicas. }\end{array}$ & BAJO & ACEPTAR \\
\hline 2 & $\begin{array}{l}\text { Podrían presentarse daños menores, con una probabilidad de ocurrencia } \\
\text { entre un } 4,17 \% \text { y } 8,33 \% \text {. No se requiere planificar acciones específicas. }\end{array}$ & MEDIO & ACEPTAR \\
\hline 3 & $\begin{array}{l}\text { Se podría afectar el funcionamiento del sistema, con una probabilidad de } \\
\text { ocurrencia entre un 8,33\% y } 25 \% \text {. El nivel de riesgo establece la necesidad } \\
\text { de adoptar medidas de control. }\end{array}$ & CRÍTICO & MITIGAR \\
\hline 4 & $\begin{array}{l}\text { Las consecuencias previstas afectan en un alto nivel el funcionamiento del } \\
\text { sistema y tienen una alta probabilidad de ocurrencia (entre 25\% y 50\%). } \\
\text { Se requieren acciones para controlar los posibles efectos. }\end{array}$ & ALTO & TRANSFERIR \\
\hline 5 & $\begin{array}{l}\text { Se prevén consecuencias extremadamente dañinas que implican la } \\
\text { desaparición del proceso y una elevada probabilidad de ocurrencia (sobre } \\
\text { el } 50 \% \text { ). Requiere de la implementación inmediata de medidas de control } \\
\text { y el estableciendo de un plan de seguimiento con el fin de eliminar la causa } \\
\text { de la amenaza. }\end{array}$ & MUY ALTO & EVITAR \\
\hline
\end{tabular}

La teoría de la gestión integral de riesgos define cuatro posibles acciones a realizar frente a la detección de un evento que podría afectar un proceso, siendo estas: aceptar, mitigar, transferir y evitar. En este caso, se define que de acuerdo al nivel del riesgo que se levante es la acción que se tomará, de este modo, si un riesgo es bajo o medio (probabilidad de ocurrencia máxima de un 8,33\%) se aceptará entendiendo que no se requieren planificar acciones específicas dado que su impacto solo representa daños menores, siendo mayor el costo de controlarlos que los beneficios. Los riesgos críticos (probabilidad de ocurrencia máxima de un $25 \%$ ) se deben mitigar (disminuir su probabilidad de ocurrencia o su impacto), los riesgos altos (probabilidad de ocurrencia máxima del $50 \%$ ) se deben transferir, y los riesgos muy altos (sobre el $50 \%$ de probabilidad de ocurrencia) se deben evitar.

Acorde a lo establecido en el marco de trabajo de la gestión de riesgos de la ISO 31.000, que indica que la definición de estos criterios debe estar alineada a la cultura de la organización y ser acorde a sus necesidades, es que la cantidad de niveles a trabajar se definió con apoyo del Auditor General de la Universidad y las definiciones de cada nivel se establecieron en conjunto con el Director General de Pregrado. Los niveles antes descritos para las amenazas, la vulnerabilidad y los riesgos permiten generar una matriz, en donde se identifique visualmente la criticidad del riesgo. El modelo genérico de ésta, a aplicar en la docencia de pregrado de la UCN se encuentra en la Figura 2.

\section{VULNERABILIDAD}

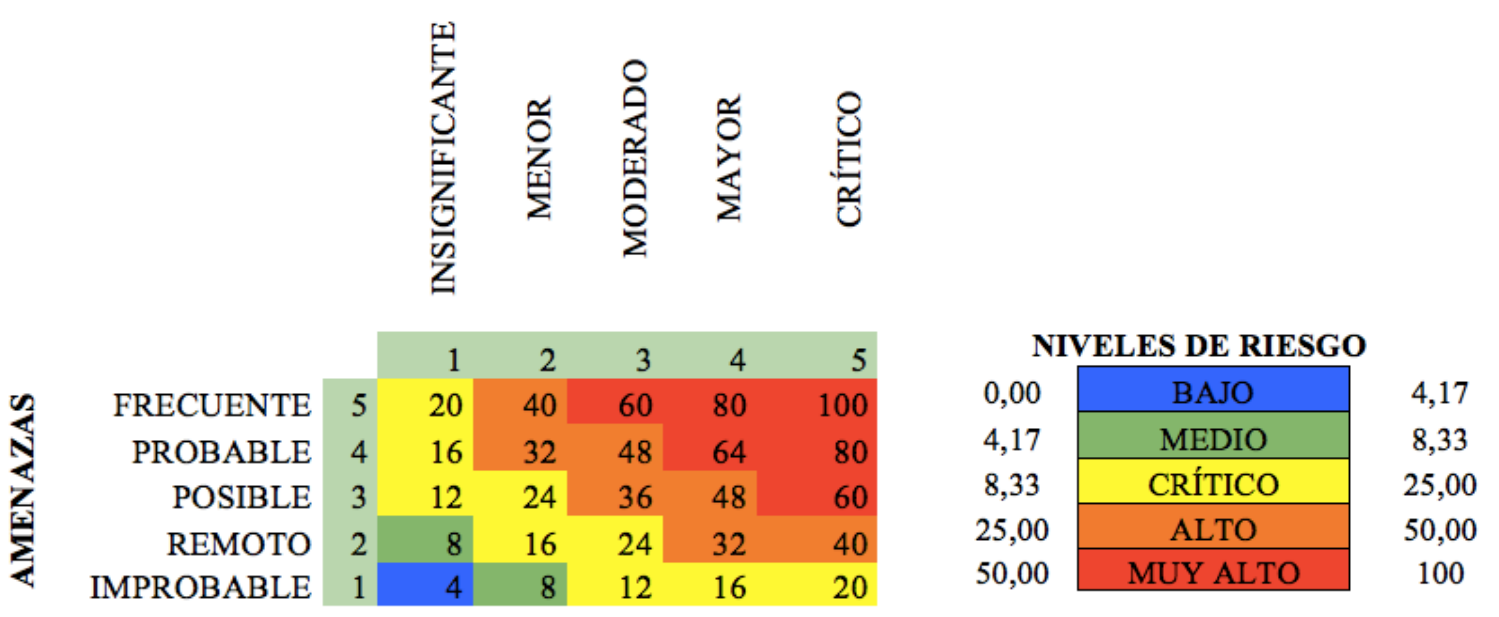

Fig. 2: Matriz de riesgos con definición de niveles de impacto

Junto con los niveles de riesgos es necesario definir los tipos de riesgos que son posibles de encontrar. De acuerdo a la teoría de gestión de riesgos, estos pueden ser del tipo operativos (fallas en la ejecución/resultados del proceso que el impiden el cumplimiento de su objetivo), financieros (eventos que afectan los resultados económicos de la organización), tecnológicos (errores en sistemas y procesamiento de 
información), de seguridad y/o medioambientales (riesgos físicos y del entorno de la organización), reputacionales (eventos que afectan la imagen/prestigio de la organización), o legales (eventos que provoquen violaciones o incumplimientos de leyes).

Con la definición de los componentes centrales del modelo de gestión de riesgos es posible realizar su aplicación en los procesos de docencia de pregrado de la UCN. Esta aplicación se basa en la realización de entrevistas a los dueños de los procesos, las que permiten levantar los riesgos que ellos observan en los procesos a partir de experiencias pasadas y de la ejecución diaria de los mismos. Cabe mencionar, que esta metodología de identificación de riesgos es principalmente del tipo cualitativa, sustentándose en la experiencia y conocimiento de los procesos por parte de los entrevistados, debido a que no se cuenta con registros de los incidentes pasados.

Se realizaron 12 entrevistas semiestructuradas con los dueños de los procesos, en las cuales se buscó validar el análisis FODA, además se presentaron los diagramas y descripciones levantados durante la autoevaluación institucional y se les solicitó indicar si estaban de acuerdo con el objetivo del sub-proceso, señalar elementos que dificultan su cumplimiento, identificar elementos claves en el proceso que de no estar lo harían fallar, señalar oportunidades de mejora a la ejecución del proceso e indicar hechos que anteriormente ha afectado la ejecución o cumplimiento del proceso (Tabla 6).

Tabla 6: Dinámica entrevista utilizada para el levantamiento de riesgos con los dueños de los sub-procesos

Objetivo: Analizar la docencia de pregrado en la UCN estableciendo los potenciales riesgos para los procesos que la componen.

Validación FODA

Se presenta un análisis FODA elaborado en base a la

autoevaluación institucional y a la evaluación del contexto realizada para la elaboración del Plan de Desarrollo Corporativo. Se discuten cada uno de los elementos de este FODA con los entrevistados y se determinan fortalezas, oportunidades, debilidades y amenazas directas sobre sus procesos.
Presentación mapa de procesos y Preguntas sobre riesgos explicación general

Se presenta un diagrama del proceso trabajado previamente en un taller institucional, validándolo, definiendo su objetivo y evaluando las distintas instancias de riesgos y control.
¿Está de acuerdo con los siguientes objetivos de los procesos de pregrado? ¿Qué elementos podrían dificultar el cumplimiento de estos objetivos?

¿Qué oportunidades de mejora detecta en el proceso actual?

¿Cuáles son los elementos que si no están el proceso falla?

\section{RESULTADOS Y DISCUSIÓN}

El trabajo de campo permitió detectar 13 riesgos en los sub-procesos críticos definidos anteriormente, siendo la dotación académica-docente el sub-proceso que más riesgos presenta (Figura 3). Se observa que los subprocesos que presentan una mayor cantidad de riesgos corresponden a dotación académica-docente y resultados de la investigación para la docencia, con 4 y 3 riesgos respectivamente. Si bien, la universidad ha realizado acciones para controlar estos riesgos, es importante, identificar que de manera natural estos elementos se vuelven críticos para el quehacer institucional, sobre todo considerando que la UCN es una universidad docente con investigación focalizada.

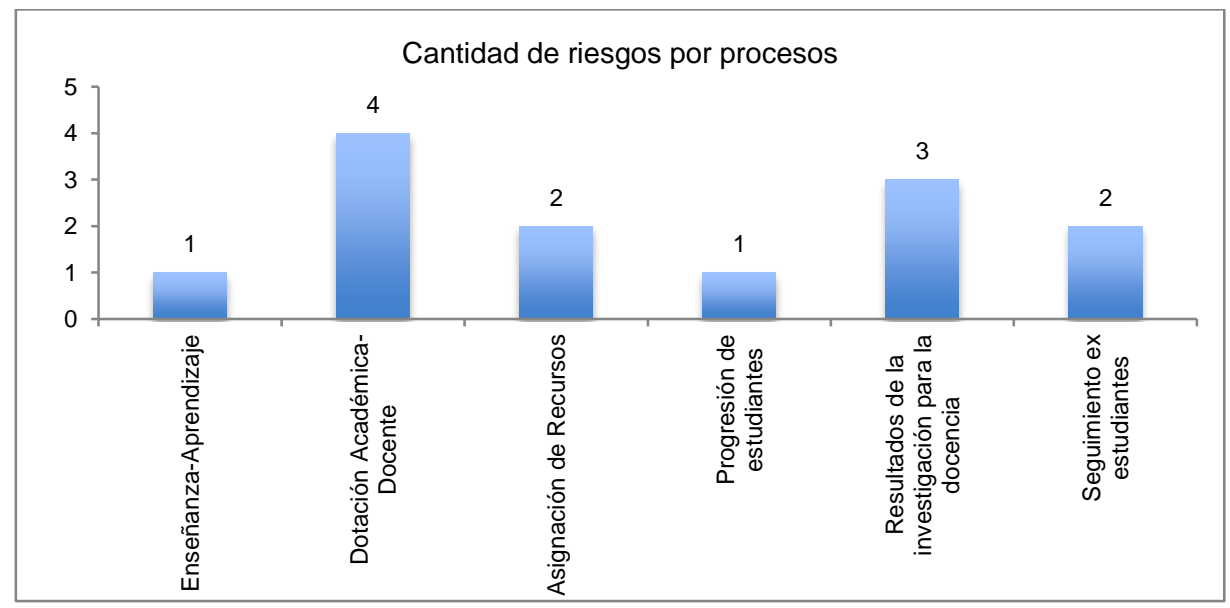

Fig. 3: Cantidad de riesgos detectados por sub-proceso 
Con respecto a la dotación académica-docente, los riesgos corresponden a la pérdida de académicos por rotación, al desinterés de académicos de las más altas jerarquías por realizar clases de pregrado (preferencia por la investigación), a aspectos a mejorar no identificados en la evaluación de desempeño y a fallas en el proceso de inducción de académicos. Estos riesgos del tipo reputacional y operativo, pueden llevar a generar fallas en la docencia de pregrado, ya que son los académicos quienes marcan las diferencia en el servicio educativo entregado en aula a los estudiantes, por lo que depende de ellos fortalecer el sello de calidad que declara la UCN, siendo fundamental que su cuerpo académico, tenga un correcto proceso de inducción, evaluación, quiera realizar clases en el pregrado y permanezca en la institución. Estas dificultades se corresponden a la debilidad de "asegurar que el perfeccionamiento de la planta académica impacte positivamente a la docencia de pregrado", y ponen en riesgo el cumplimiento de los objetivos estratégicos de "mejorar el desempeño de carreras y programas" y de "fortalecer las capacidades docentes de la planta oficial, especial y profesores hora", declarados en el PDC 2015-2019, afectando directamente a la acreditación de carreras e institucional.

Con respecto a la vinculación de la investigación y la docencia, se observa que los riesgos son operativos, puesto que se forjan a partir de la falta de presupuesto que genera una dependencia de fondos externos para la realización de proyectos; de la falta de difusión para la actividades de investigación y de fallas en el proceso de postulación a proyectos. En la medida que este sub-proceso se encuentre fortalecido, será más fácil la integración de estudiantes a proyectos y actividades de investigación, que permitan reportar resultados para mejorar la docencia de pregrado y que apoyen a superar la debilidad declarada en ésta área. Además, los riesgos detectados podrían afectar el cumplimiento de objetivos estratégicos tanto del área de docencia de pregrado, como del área de investigación, es decir, afecta dos ejes de la acreditación institucional. Si bien, estos sub-procesos concentran la mayor cantidad de riesgos, es importante, reconocer que la acreditación institucional, como mecanismo de aseguramiento de calidad evalúa más ejes de la docencia de pregrado, incluyendo los procesos de enseñanza-aprendizaje, asignación de recursos, progresión de estudiantes y seguimiento de ex estudiantes. Además, en función de las acciones realizadas por la institución, estos riesgos pueden mantenerse o controlarse, pudiendo seguir siendo críticos o centrándose la atención en otros subprocesos. De este modo, a continuación se analizan todos los riesgos de estos sub-procesos, a partir, de la información entregada por los dueños de los procesos en las entrevistas, la que permite establecer tipos de riesgos, amenazas que generan los riesgos y su causas (ver Tabla 7).

A su vez, se definen las consecuencias de estos posibles riesgos y el impacto que tendría en la organización, indicando aquellos objetivos e indicadores del eje Proyecto Educativo del PDC 2015-2019 que se podrían ver afectados (ver Tabla 8). Se observa que los objetivos que se podrían ver mayormente afectados en su cumplimiento son "mejorar el desempeño de carreras y programas" junto con "asegurar la calidad de la formación del pregrado y postgrado", dada la cantidad de veces que se repiten en el análisis. A su vez, el indicador, más crítico corresponde a "años de acreditación de carreras". Al evaluar los riesgos descritos en función de los niveles de amenazas y de vulnerabilidad definidos previamente (Tablas 3 y 4) es posible hacer una primera clasificación de los riesgos inherentes en los procesos, es decir, sin evaluar las medidas de control ya establecidas por la UCN. Se observa que existen 7 riesgos de nivel muy alto, 3 en nivel alto y 3 en nivel críticos. Además, es posible confeccionar una matriz de riesgos iniciales o inherentes (ver Figura 4).

Aquí se observa que sin aplicar ningún control el riesgo más alto (R8) está dado por la imposibilidad de sostener equipos de trabajo a nivel institucional siendo parte del proceso progresión de estudiantes, este riesgo nace de la contratación del equipo de nivelación y apoyo estudiantil de la UCN a través de proyectos externos. El trabajo de este equipo ha permitido aumentar las tasas de retención del primer año y favorecer la progresión de los estudiantes, afectando su pérdida al cumplimiento de los objetivos e indicadores establecidos en el PDC 2015-2019 y al Proyecto Educativo de la Institución. Es necesario considerar que la UCN ya ha implementado algunos controles sobre estos procesos que permiten minimizar sus riesgos. Estos controles han sido evaluados, permitiendo disminuir los niveles de probabilidad y/o impacto, dando origen a un riesgo residual, que es el que se observa en los procesos actuales (Figura 5). Con la aplicación de estos controles se obtiene 1 riesgo en nivel muy alto, 6 en nivel alto y 6 en nivel crítico, observando que estos se alejan de la zona roja de la matriz (nivel muy alto) y pasan a una zona naranja (nivel alto). El riesgo R8, por ejemplo, se traslada hacia la zona naranja (nivel alto), quedando solo en la zona roja (nivel muy alto) la baja vinculación con egresados/falta de contactos en el medio (R12).

Tabla 7: Riesgos y amenazas encontrados en la Docencia de Pregrado UCN

\begin{tabular}{|c|l|l|l|l|l|}
\hline ID & \multicolumn{1}{|c|}{ Sub-Proceso } & \multicolumn{1}{|c|}{ Amenaza } & \multicolumn{1}{c|}{ Causa } & EVENTO (RIESGO) & $\begin{array}{c}\text { Tipo de } \\
\text { riesgo }\end{array}$ \\
\hline R1 & $\begin{array}{l}\text { Enseñanza- } \\
\text { Aprendizaje }\end{array}$ & $\begin{array}{l}\text { Falta de } \\
\text { recursos }\end{array}$ & $\begin{array}{l}\text { Presupuesto } \\
\text { histórico }\end{array}$ & $\begin{array}{l}\text { Fallas en aplicación del } \\
\text { proceso }\end{array}$ & Operativo \\
\hline
\end{tabular}


Tabla 7 (continuación)

\begin{tabular}{|c|c|c|c|c|c|}
\hline$I D$ & Sub-Proceso & Amenaza & Causa & $\begin{array}{l}\text { EVENTO } \\
\text { (RIESGO) }\end{array}$ & $\begin{array}{l}\text { Tipo de } \\
\text { riesgo }\end{array}$ \\
\hline $\mathrm{R} 2$ & $\begin{array}{l}\text { Dotación Académica- } \\
\text { Docente }\end{array}$ & $\begin{array}{l}\text { Rotación de } \\
\text { académicos }\end{array}$ & $\begin{array}{l}\text { Condiciones de } \\
\text { ciudad/imposibilidad de } \\
\text { sostener renta acorde al } \\
\text { mercado }\end{array}$ & $\begin{array}{l}\text { Pérdida de } \\
\text { académicos }\end{array}$ & Reputacional \\
\hline R3 & $\begin{array}{l}\text { Dotación Académica- } \\
\text { Docente }\end{array}$ & $\begin{array}{l}\text { Estímulos a } \\
\text { docentes para } \\
\text { trabajar en } \\
\text { investigación }\end{array}$ & Bonificación externa & $\begin{array}{l}\text { Disminución de } \\
\text { carga docente en } \\
\text { académicos } \\
\text { (desinterés) }\end{array}$ & Operativo \\
\hline $\mathrm{R} 4$ & $\begin{array}{l}\text { Dotación Académica- } \\
\text { Docente }\end{array}$ & $\begin{array}{l}\text { Aplicación } \\
\text { incorrecta } \\
\text { evaluación de } \\
\text { desempeño }\end{array}$ & $\begin{array}{l}\text { Procedimiento poco } \\
\text { riguroso }\end{array}$ & $\begin{array}{l}\text { Aspectos a mejorar } \\
\text { no identificados en } \\
\text { evaluación de } \\
\text { desempeño }\end{array}$ & Operativo \\
\hline R5 & $\begin{array}{l}\text { Dotación Académica- } \\
\text { Docente }\end{array}$ & $\begin{array}{l}\text { Falta de } \\
\text { comunicación de } \\
\text { procesos de nivel } \\
\text { central }\end{array}$ & $\begin{array}{l}\text { Descoordinación entre } \\
\text { unidades }\end{array}$ & $\begin{array}{l}\text { Fallas (no } \\
\text { realización) } \\
\text { proceso de } \\
\text { inducción de } \\
\text { académicos }\end{array}$ & Operativo \\
\hline R6 & $\begin{array}{l}\text { Asignación de } \\
\text { Recursos }\end{array}$ & $\begin{array}{l}\text { Falta de } \\
\text { disponibilidad de } \\
\text { recursos }\end{array}$ & Presupuesto & $\begin{array}{l}\text { Entrega de } \\
\text { recursos tardía }\end{array}$ & Financiero \\
\hline $\mathrm{R} 7$ & $\begin{array}{l}\text { Asignación de } \\
\text { Recursos }\end{array}$ & $\begin{array}{l}\text { Condiciones } \\
\text { inadecuadas de } \\
\text { infraestructura }\end{array}$ & Presupuesto & $\begin{array}{l}\text { Fallas en } \\
\text { investigaciones } \\
\text { (laboratorios) }\end{array}$ & Operativo \\
\hline R8 & $\begin{array}{l}\text { Progresión de } \\
\text { estudiantes }\end{array}$ & $\begin{array}{l}\text { Personal } \\
\text { contratado con } \\
\text { proyectos externos }\end{array}$ & $\begin{array}{l}\text { Falta aprobación a } \\
\text { modificación de } \\
\text { organigrama }\end{array}$ & $\begin{array}{l}\text { Imposibilidad de } \\
\text { sostener equipos } \\
\text { de trabajo a nivel } \\
\text { institucional }\end{array}$ & Reputacional \\
\hline R9 & $\begin{array}{l}\text { Resultados de la } \\
\text { investigación para la } \\
\text { docencia }\end{array}$ & $\begin{array}{l}\text { Dependencia de } \\
\text { fondos externos/ } \\
\text { Falta de fondos } \\
\text { centrales }\end{array}$ & Presupuesto & $\begin{array}{l}\text { Bajos resultados en } \\
\text { proyectos de } \\
\text { investigación }\end{array}$ & Operativo \\
\hline $\mathrm{R} 10$ & $\begin{array}{l}\text { Resultados de la } \\
\text { investigación para la } \\
\text { docencia }\end{array}$ & $\begin{array}{l}\text { Falta de difusión de } \\
\text { actividades }\end{array}$ & $\begin{array}{l}\text { Incorrecta definición de } \\
\text { responsabilidades }\end{array}$ & $\begin{array}{l}\text { Baja participación } \\
\text { en actividades de } \\
\text { investigación }\end{array}$ & Operativo \\
\hline $\mathrm{R} 11$ & $\begin{array}{l}\text { Resultados de la } \\
\text { investigación para la } \\
\text { docencia }\end{array}$ & $\begin{array}{l}\text { Alta dependencia } \\
\text { de personas para la } \\
\text { ejecución del } \\
\text { proceso }\end{array}$ & $\begin{array}{l}\text { Falta documentación } \\
\text { proceso }\end{array}$ & $\begin{array}{l}\text { Pérdida de } \\
\text { postulaciones a } \\
\text { proyectos }\end{array}$ & Operativo \\
\hline $\mathrm{R} 12$ & $\begin{array}{l}\text { Seguimiento ex } \\
\text { estudiantes }\end{array}$ & $\begin{array}{l}\text { Falta de } \\
\text { reportabilidad } \\
\text { sistema }\end{array}$ & Integración de procesos & $\begin{array}{l}\text { Baja vinculación } \\
\text { con egresados/falta } \\
\text { de contactos en el } \\
\text { medio (a) }\end{array}$ & Reputacional \\
\hline $\mathrm{R} 13$ & $\begin{array}{l}\text { Seguimiento ex } \\
\text { estudiantes }\end{array}$ & $\begin{array}{l}\text { Falta de } \\
\text { estandarización de } \\
\text { registros en } \\
\text { unidades } \\
\text { académicas }\end{array}$ & Proceso no definido & $\begin{array}{l}\text { Baja vinculación } \\
\text { con egresados/falta } \\
\text { de contactos en el } \\
\text { medio (b) }\end{array}$ & Reputacional \\
\hline
\end{tabular}


Tabla 8: Impacto de riesgos e indicadores del PDC afectados

\begin{tabular}{|c|c|c|c|c|c|}
\hline$I D$ & Evento (Riesgo) & Consecuencia & Impacto & $\begin{array}{l}\text { Objetivo } \\
\text { PDC } \\
\text { (PEI) }\end{array}$ & $\begin{array}{l}\text { Indicador } \\
\text { PDC (PEI) }\end{array}$ \\
\hline R1 & $\begin{array}{l}\text { Fallas en aplicación del } \\
\text { proceso }\end{array}$ & $\begin{array}{l}\text { Incorrecta aplicación de metodologías de } \\
\text { enseñanza }\end{array}$ & $\begin{array}{l}\text { Pérdida de } \\
\text { estudiantes }\end{array}$ & $2,4,5$ & O4: 12 \\
\hline $\mathrm{R} 2$ & Pérdida de académicos & Disminución de indicadores docentes & $\begin{array}{l}\text { Pérdida de } \\
\text { estudiantes }\end{array}$ & 4 & O4: I1 \\
\hline R3 & $\begin{array}{l}\text { Disminución de carga } \\
\text { docente en académicos } \\
\text { (desinterés) }\end{array}$ & $\begin{array}{l}\text { Menores rendimientos en estudiantes de } \\
\text { primeros años / incumplimiento } \\
\text { indicadores PDC }\end{array}$ & $\begin{array}{l}\text { Pérdida de } \\
\text { estudiantes }\end{array}$ & $2,3,5$ & O3: I3 \\
\hline $\mathrm{R} 4$ & $\begin{array}{l}\text { Aspectos a mejorar no } \\
\text { identificados en } \\
\text { evaluación de desempeño }\end{array}$ & $\begin{array}{l}\text { Menores rendimientos en estudiantes de } \\
\text { primeros años / incumplimiento } \\
\text { indicadores PDC }\end{array}$ & $\begin{array}{l}\text { Pérdida de } \\
\text { estudiantes }\end{array}$ & $2,3,4$ & $\begin{array}{l}\text { O3: } 12 \\
\text { O4: } 12\end{array}$ \\
\hline R5 & $\begin{array}{l}\text { Fallas (no realización) } \\
\text { proceso de inducción de } \\
\text { académicos }\end{array}$ & $\begin{array}{l}\text { Desconocimiento institución por parte de } \\
\text { docentes }\end{array}$ & $\begin{array}{l}\text { Pérdida de } \\
\text { competitividad }\end{array}$ & - & - \\
\hline R6 & Entrega de recursos tardía & $\begin{array}{l}\text { Soporte de carreras (infraestructura, } \\
\text { equipamiento, docentes) inadecuado }\end{array}$ & $\begin{array}{l}\text { Pérdida de } \\
\text { estudiantes }\end{array}$ & 1,2 & $\begin{array}{l}\text { O1: } 11 \\
\text { O2: } 12\end{array}$ \\
\hline R7 & $\begin{array}{l}\text { Fallas en investigaciones } \\
\text { (laboratorios) }\end{array}$ & Incumplimiento indicador PDC & $\begin{array}{l}\text { Pérdida de } \\
\text { competitividad }\end{array}$ & $2,3,5$ & O5: I1 \\
\hline R8 & $\begin{array}{l}\text { Imposibilidad de sostener } \\
\text { equipos de trabajo a nivel } \\
\text { institucional }\end{array}$ & Incumplimiento indicador PDC & $\begin{array}{l}\text { Pérdida de } \\
\text { competitividad }\end{array}$ & 2,4 & O4: 12,13 \\
\hline R9 & $\begin{array}{l}\text { Bajos resultados en } \\
\text { proyectos de investigación }\end{array}$ & Incumplimiento indicador PDC & $\begin{array}{l}\text { Pérdida de } \\
\text { competitividad }\end{array}$ & $2,3,4$ & $\begin{array}{l}\text { O3: } 11,12, \\
\text { O4:, I2 }\end{array}$ \\
\hline $\mathrm{R} 10$ & $\begin{array}{l}\text { Baja participación en } \\
\text { actividades de } \\
\text { investigación }\end{array}$ & Incumplimiento indicador PDC & $\begin{array}{l}\text { Pérdida de } \\
\text { competitividad }\end{array}$ & $2,3,5$ & - \\
\hline $\mathrm{R} 11$ & $\begin{array}{l}\text { Pérdida de postulaciones } \\
\text { a proyectos }\end{array}$ & Incumplimiento indicador PDC & $\begin{array}{l}\text { Pérdida de } \\
\text { competitividad }\end{array}$ & 2,4 & O4: 12 \\
\hline R12 & $\begin{array}{l}\text { Baja vinculación con } \\
\text { egresados/falta de } \\
\text { contactos en el medio (a) }\end{array}$ & Incumplimiento indicador PDC & $\begin{array}{l}\text { Pérdida de } \\
\text { competitividad }\end{array}$ & - & - \\
\hline R13 & $\begin{array}{l}\text { Baja vinculación con } \\
\text { egresados/falta de } \\
\text { contactos en el medio (b) }\end{array}$ & Incumplimiento indicador PDC & $\begin{array}{l}\text { Pérdida de } \\
\text { competitividad }\end{array}$ & 4 & - \\
\hline
\end{tabular}

\section{MATRIZ DE RIEGOS INHERENTES (si no existieran controles)}

\section{VULNERABILIDAD}
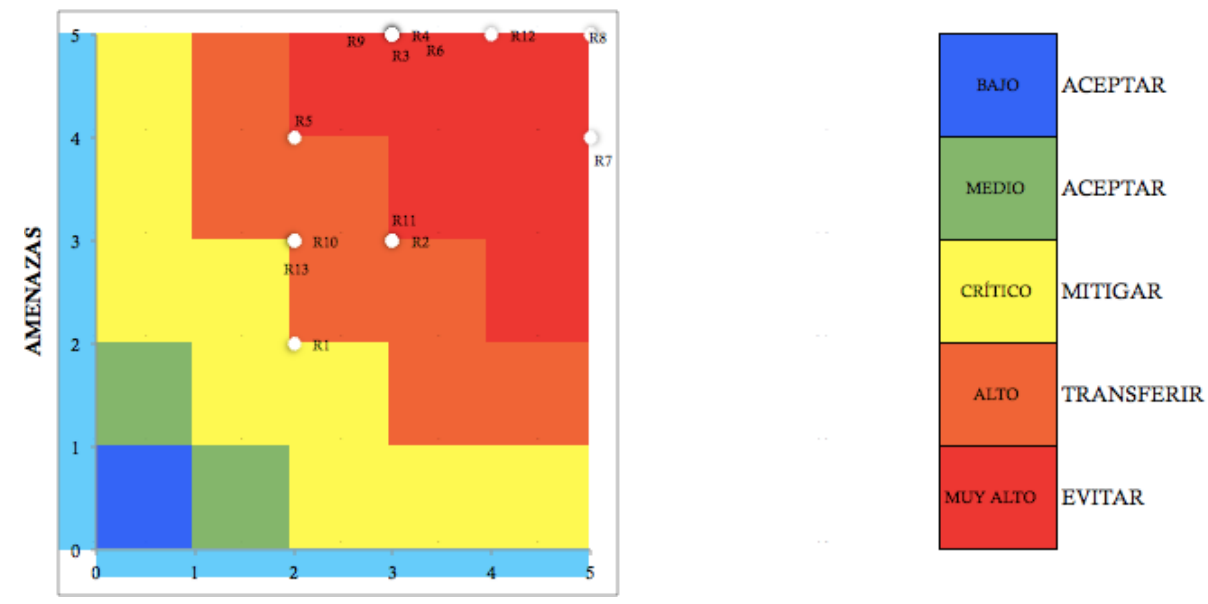

Fig. 4: Matriz de riesgos iniciales de la Docencia de Pregrado UCN 
MATRIZ DE RIEGOS ACTUALES (considera la estructura de control actual de la organización)
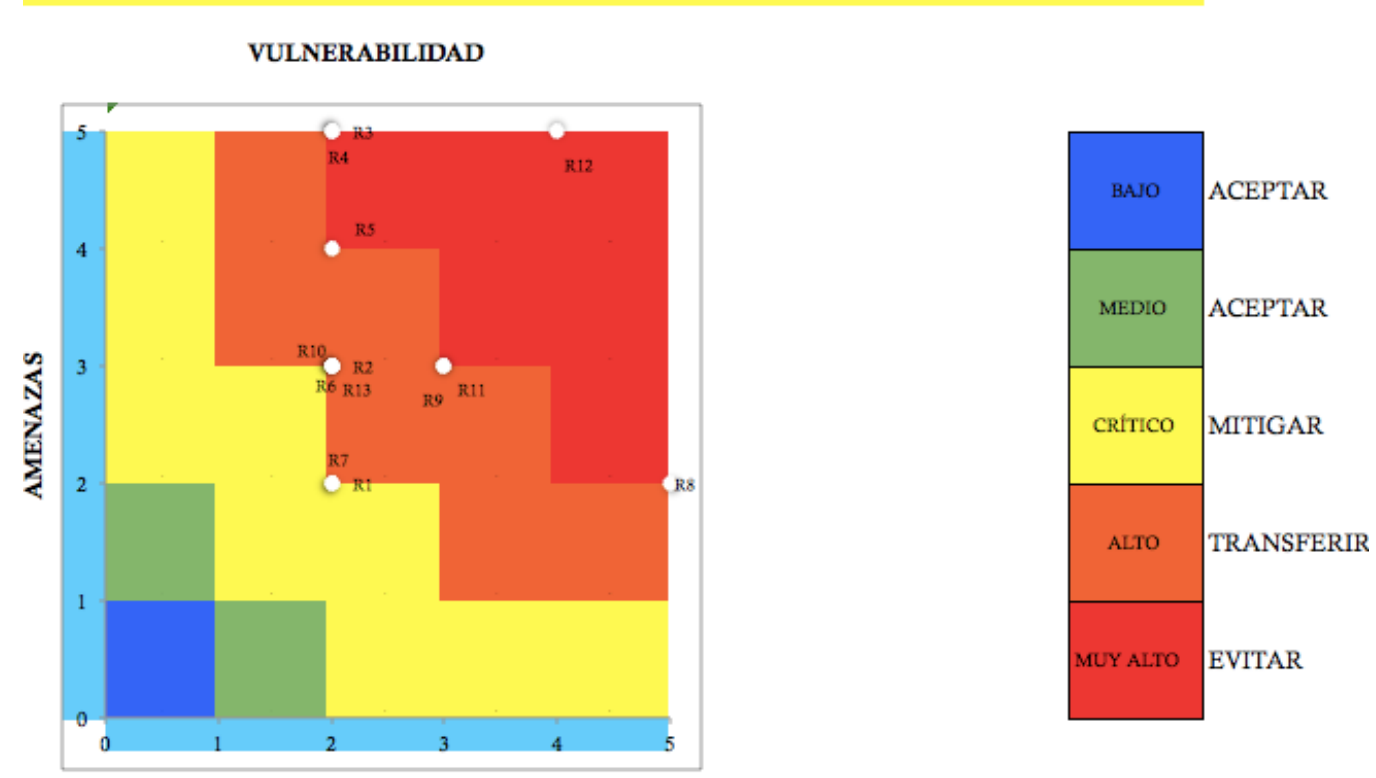

Fig. 5: Matriz de riesgos residuales de la Docencia de Pregrado UCN

En la gestión de riesgos se busca que los riesgos no aceptados se eviten, transfieran o mitiguen de forma que tengan el menor impacto y/o probabilidad posible. Es por ello, que a continuación se proponen una serie de acciones (con plazos y responsables), junto a indicadores claves de riesgos (KRI) con el fin de generar un nuevo control sobre los procesos evitando el incumplimiento de los objetivos e indicadores del PDC señalados anteriormente (ver Tabla 9). A partir de una evaluación posterior a su aplicación, los riesgos deberían desplazarse hacia la zona azul/verde de la matriz.

A partir de la evaluación de los riesgos residuales, es posible observar que los cuatro principales riesgos que presenta la docencia de pregrado en la UCN corresponden a la baja vinculación con egresados de la institución, la imposibilidad de sostener equipos de trabajos a nivel institucional, aspectos a mejorar no identificados en la evaluación de desempeño de los académicos y el desinterés de los académicos de jerarquías superiores por tomar asignaturas de pregrado en la universidad, correspondientes a los subprocesos de seguimiento de ex estudiantes, progresión de estudiantes y dotación académica-docente respectivamente. Estos cuatro elementos son riesgos del tipo reputacional y operativos que afectan la satisfacción del estudiante en su proceso formativo y por lo tanto, afectan al cumplimiento de la misión y visión de la organización. Por esta razón se plantean indicadores claves de riesgos que permiten monitorear el control del riesgo de acuerdo al contexto de la institución.

El riesgo que presenta una mayor probabilidad de ocurrencia es "baja vinculación con los egresados / falta de contactos en el medio". Este riesgo se presenta como una debilidad en el análisis FODA descrita como "aumentar la vinculación con el medio (contacto con empresas)", pese a que también existe la oportunidad de "generación de clúster y asociaciones de vinculación con empresas de la zona". Es decir, se reconoce que se debe fortalecer la vinculación con el medio y que existen oportunidades para ello, no obstante, no se han logrado los resultados esperados en este tema. Este riesgo nace, porque la vinculación con egresados y el medio históricamente se ha realizado al interior de cada unidad académica, de distintas maneras y con distintos resultados. Solo en el último tiempo se crea una unidad central encargada de la vinculación y se buscan generar registros centralizados, que permitan el contacto con egresados y actores relevantes para fortalecer los servicios prestados por la institución, como lo son empresas del sector, el medio regional y nacional, entre otros, ya que su opinión permite generar una retroalimentación y proponer cambios y actualización de mallas curriculares, realizar evaluaciones de acreditación de carreras y mejorar los diversos servicios prestados por la institución.

Si bien existe un área de evaluación en la acreditación institucional que se dedica por completo a la vinculación con el medio, y un apartado del PDC 2015-2019 que plantea objetivos e indicadores específicos para este tema; desde el punto de vista de la docencia de pregrado, es clave la integración de los resultados de la vinculación a los procesos formativos de los estudiantes, en los distintos programas y carreras que se imparten. La vinculación permite tener una retroalimentación del entorno, pero también fortalece lazos para que los estudiantes realicen sus prácticas profesionales, trabajos en terreno, actividades de titulación y cuenten con instancias de acercamiento al medio laboral en que se desenvolverán al concluir sus estudios. 
Desde el punto de vista académico, la vinculación facilita la creación de conocimiento en conjunto con las empresas, y desde el punto de vista directivo y estratégico de la universidad, permite una mejor comprensión del entorno para la generación de la oferta académica de acuerdo a las necesidades regionales y nacionales, y la planificación de su quehacer en el corto, mediano y largo plazo.

Por otra parte, la capacidad de sostener equipos de apoyo y nivelación a nivel institucional, es un riesgo que disminuye desde nivel muy alto, a nivel alto, gracias a la postulación de proyectos con financiamiento externos para el equipo. No obstante, esta actividad de mitigación no es suficiente, ya que el control del riesgo no queda a cargo de la organización, sino que va a depender de los resultados de los proyectos en que se postule. Este equipo de nivelación que tiene 4 años de funcionamiento, trabaja en el apoyo psicoeducativo de los estudiantes, lo que ha permitido disminuir la deserción del primer año y aumentar las tasas de aprobación, disminuyendo las brechas de ingreso de los estudiantes. Por lo tanto, su imposibilidad de operar afectaría los indicadores de tasa de titulación oportuna y tasas de retención, junto a los objetivos estratégicos de "mejorar el desempeño de carreras y programas" y "asegurar la calidad de la formación del pregrado y postgrado".

Tabla 9: KRI y plan de acción para riesgos para riesgos de la Docencia de Pregrado UCN

\begin{tabular}{|c|c|c|c|c|c|c|c|c|}
\hline ld & Evento (Riesgo) & $\begin{array}{l}\text { Ran- } \\
\text { king }\end{array}$ & $\begin{array}{l}\text { Tipo } \\
\text { Acción }\end{array}$ & Acción & $\begin{array}{l}\text { Respon- } \\
\text { sable }\end{array}$ & Plazo & $\begin{array}{l}\text { Kri (Indicador de } \\
\text { Riesgo) }\end{array}$ & Valor \\
\hline R1 & $\begin{array}{l}\text { Fallas en aplicación del } \\
\text { proceso }\end{array}$ & 12 & Mitigar & $\begin{array}{l}\text { Control de metodologías } \\
\text { en sala }\end{array}$ & VRA & 2017 & $\begin{array}{l}\% \text { de } \\
\text { metodologías } \\
\text { activas }\end{array}$ & $>40 \%$ \\
\hline $\mathrm{R} 2$ & Pérdida de académicos & 8 & Mitigar & $\begin{array}{l}\text { Formación de egresados } \\
\text { UCN }\end{array}$ & $\begin{array}{l}\text { Unida- } \\
\text { des }\end{array}$ & 2019 & $\begin{array}{l}\text { Vacantes } \\
\text { disponibles para } \\
\text { académicos }\end{array}$ & $<2 \%$ \\
\hline R3 & $\begin{array}{l}\text { Disminución de carga } \\
\text { docente en académicos } \\
\text { (desinterés) }\end{array}$ & 2 & Transferir & $\begin{array}{l}\text { Generar incentivos hacia } \\
\text { la docencia } \\
\text { (formalización) }\end{array}$ & VRA & 2018 & $\begin{array}{l}\text { \% de académicos } \\
\text { planta que } \\
\text { realizan docencia } \\
\text { de pregrado }\end{array}$ & $\overrightarrow{90 \%}$ \\
\hline R4 & $\begin{array}{l}\text { Aspectos a mejorar no } \\
\text { identificados en } \\
\text { evaluación de } \\
\text { desempeño }\end{array}$ & 2 & Transferir & $\begin{array}{l}\text { Evaluar y actualizar } \\
\text { mecanismo de } \\
\text { evaluación de } \\
\text { desempeño }\end{array}$ & VRA & 2018 & $\begin{array}{l}\% \text { académicos no } \\
\text { evaluados }\end{array}$ & $<5 \%$ \\
\hline R5 & $\begin{array}{l}\text { Fallas (no realización) } \\
\text { proceso de inducción de } \\
\text { académicos }\end{array}$ & 7 & Transferir & $\begin{array}{l}\text { Asociar información de } \\
\text { inducción a la generación } \\
\text { de claves de acciones } \\
\text { iniciales }\end{array}$ & $\begin{array}{l}\text { VAEA - } \\
\text { RRHH }\end{array}$ & 2017 & $\begin{array}{l}\text { \% de nuevos } \\
\text { académicos con } \\
\text { inducción }\end{array}$ & $>95 \%$ \\
\hline R6 & $\begin{array}{l}\text { Entrega de recursos } \\
\text { tardía }\end{array}$ & 8 & Mitigar & $\begin{array}{l}\text { Incentivo a participación } \\
\text { en proyectos de } \\
\text { financiamiento externo }\end{array}$ & DGPRE & 2017 & $\begin{array}{l}\% \text { unidades que } \\
\text { postulan a } \\
\text { financiamiento } \\
\text { externo }\end{array}$ & $>30 \%$ \\
\hline R7 & $\begin{array}{l}\text { Fallas en } \\
\text { investigaciones } \\
\text { (laboratorios) }\end{array}$ & 12 & Mitigar & $\begin{array}{l}\text { Establecimiento de } \\
\text { políticas de condiciones } \\
\text { mínimas de uso de } \\
\text { talleres para } \\
\text { investigación }\end{array}$ & VRIDT & 2017 & $\begin{array}{l}\% \text { laboratorios con } \\
\text { fallas }\end{array}$ & $<5 \%$ \\
\hline R8 & $\begin{array}{l}\text { Imposibilidad de } \\
\text { sostenter equipos de } \\
\text { trabajo a nivel } \\
\text { institucional }\end{array}$ & 2 & Transferir & $\begin{array}{l}\text { Revisar estructura } \\
\text { orgánica pregrado }\end{array}$ & VRA & 2017 & $\begin{array}{l}\% \text { de } \\
\text { contrataciones por } \\
\text { proyectos } \\
\text { externos }\end{array}$ & $<15 \%$ \\
\hline R9 & $\begin{array}{l}\text { Bajos resultados en } \\
\text { proyectos de } \\
\text { investigación }\end{array}$ & 5 & Transferir & $\begin{array}{l}\text { Aumentar proyección de } \\
\text { presupuesto anual de } \\
\text { investigación }\end{array}$ & VRIDT & 2019 & $\begin{array}{l}\text { Aumento en \% de } \\
\text { proyectos } \\
\text { adjudicados }\end{array}$ & $\begin{array}{l}>5 \% \\
\text { anual }\end{array}$ \\
\hline R10 & $\begin{array}{l}\text { Baja participación en } \\
\text { actividades de } \\
\text { investigación }\end{array}$ & 8 & Mitigar & $\begin{array}{l}\text { Actualización del proceso } \\
\text { de postulación a } \\
\text { proyectos }\end{array}$ & VRIDT & 2017 & $\begin{array}{l}\% \text { de proyectos } \\
\text { presentados fuera } \\
\text { de tiempo }\end{array}$ & $<2 \%$ \\
\hline R11 & $\begin{array}{l}\text { Pérdida de } \\
\text { postulaciones a } \\
\text { proyectos }\end{array}$ & 5 & Transferir & $\begin{array}{l}\text { Levantar y oficiar } \\
\text { proceso y procedimientos }\end{array}$ & VRIDT & 2017 & $\begin{array}{l}\text { \% de proyectos no } \\
\text { adjudicados fuera } \\
\text { de base }\end{array}$ & $<2 \%$ \\
\hline R12 & $\begin{array}{l}\text { Baja vinculación con } \\
\text { egresados/falta de } \\
\text { contactos en el medio } \\
\text { (a) }\end{array}$ & 1 & Evitar & $\begin{array}{l}\text { Actualización de } \\
\text { plataforma }\end{array}$ & DGVM & 2018 & $\begin{array}{l}\% \text { de egresados } \\
\text { actualizados en el } \\
\text { sistema }\end{array}$ & $>40 \%$ \\
\hline R13 & $\begin{array}{l}\text { Baja vinculación con } \\
\text { egresados/falta de } \\
\text { contactos en el } \\
\text { medio (b) }\end{array}$ & 8 & Mitigar & Creación de estándares & DGVM & 2018 & $\begin{array}{l}\% \text { de unidades } \\
\text { que registran } \\
\text { egresados en } \\
\text { formato }\end{array}$ & $>95 \%$ \\
\hline
\end{tabular}


Finalmente, con respecto a la dotación académica-docente, una vez aplicados controles, los dos riesgos que se deben monitorear corresponden a aspectos a mejorar no identificados en la evaluación de desempeño de los académicos y el desinterés de los académicos de jerarquías superiores por tomar asignaturas de pregrado en la universidad, por las razones analizadas previamente. Este instrumento de identificación y control de riesgos, que responde a la metodología de investigación- acción es posible de replicar en las otras áreas de la acreditación institucional, con el fin de ser integrado a un sistema de gestión de calidad que considere los riesgos de acuerdo a lo establecido por la norma ISO 9001:2015 y en base a los principios de la norma ISO 31:000.

\section{DISCUSIÓN FINAL}

La gestión de riesgos se vuelve un elemento estratégico en la organización porque permite determinar los eventos que afectan la consecución de los objetivos de los procesos y que presentan un impacto en los planes estratégicos de la institución.

La ISO 31.000 da un marco de referencia para la gestión integral de riesgos estableciendo principios de trabajo y señalando que la identificación, evaluación y monitoreo de los riesgos debe ser un proceso sistemático en la organización que cuente con procedimientos y prácticas definidas.

Las matrices de riesgo son las formas más comunes de evaluación de riesgo por su fácil aplicabilidad y comprensión. No obstante, es necesario que la determinación de sus niveles considere el contexto de la organización.

El objetivo de proponer un modelo de gestión de riesgos para el área docencia de pregrado de la UCN se cumple, a través de la definición de los elementos de las matrices de riesgos de acuerdo al horizonte de tiempo del Plan de Desarrollo Corporativo de la institución, para luego realizar la aplicación sobre los subprocesos claves, estableciendo riesgos inherentes y residuales, junto a medidas de control.

Se detecta que el principal riesgo de la docencia de pregrado de la UCN, corresponde a la falta de vinculación con los egresados y la generación de contactos con el medio, los cuales permiten retroalimentar a las carreras de su proceso formativo y realizar actividades de extensión de nutran la formación de los estudiantes, esto debido a la falta de sistematización de los datos de los egresados y el medio. Por otra parte, existe una fuerte amenaza de falla en el sub-proceso de progresión de los estudiantes que está dada por la incapacidad de sostener equipos de apoyo y nivelación a estudiantes de primer año a nivel institucional, ya que actualmente su financiamiento se realiza con proyectos externos. En tercer lugar, el sub-proceso de dotación académicadocente presenta falencias en la evaluación de desempeño y en la realización de clases por parte de los académicos de las más altas jerarquías en el pregrado.

Estos riesgos de tipo operativos y reputacionales podrían afectar los objetivos estratégicos para el eje Proyecto Educativo del Plan de Desarrollo Corporativo 2015-2019 de la institución, junto a diferentes indicadores que tienen un impacto tanto en la gestión de las carreras, como en los resultados de la gestión de la universidad, afectando las acreditaciones por programas/carreras y la institucional.

Este estudio permite generar un modelo de evaluación de riesgos replicable en las diferentes áreas de las instituciones de educación superior, favoreciendo sus resultados de acreditación, ya que los procesos evaluados corresponden a los definidos por la CNA para la realización de la autoevaluación institucional. En este sentido, es un mecanismo de aseguramiento de la calidad y favorece la gestión de la organización para la formación de profesionales, a la vez, que permite una mejor entrega del servicio a los estudiantes.

La evaluación de los riesgos favorece la gestión integra de la organizaciones, mejorando su conocimiento y el funcionamiento de sus procesos, por lo que se espera que este estudio refuerce las acciones de seguimiento y control ya establecidas por la casa de estudios evaluada.

\section{CONCLUSIONES}

La gestión de riesgos se ha tornado fundamental en las organizaciones de hoy y varios cursos y estudios que aborda el uso de las normas ISO 31000 con el propósito de mejorar la calidad de estas organizaciones. Sin embargo el uso de estas herramientas es muy bajo en las instituciones de educación superior en Chile. Este estudio muestra los beneficios del uso de la norma ISO 31000 para mejoras de los procesos docentes en una universidad con miras a mejorar la acreditación tanto institucional como de sus programas. Este proceso se aborda en forma sistemática siguiendo la normativa y sus principios fundamentales bordado este proceso en forma sistemática 
Este estudio aporta a las universidades con una guía práctica, detallada y sistemática de la identificación, evaluación y monitoreo de los riesgos a nivel de la gestión docente con miras a la formulación de estrategias que permita de mejor manera la toma de decisiones tendientes a evitar, transferir o mitigar los riesgos encontrados. Asimismo, este resultado permite una mejora en la gestión central de las universidades y la construcción de escenarios posibles antes eventualidades ya identificadas que van más allá del ámbito estrictamente financiero como se ha evaluado tradicionalmente. Se destaca la necesidad de ubicar la gestión de riesgos como un pilar fundamental en la gestión docente, centrada en las definiciones estratégicas de la institución y apoyada por los niveles directivos de la misma.

Una limitante de la investigación es que este estudio se desarrolló a nivel exploratorio, dada la inexistencia de aplicaciones en el entorno de Instituciones de Educación Superior en Chile, por lo que este modelo solo ha sido evaluado en una organización, teniendo pendiente su puesta en marcha, por lo que se hace necesario replicar este trabajo en otras áreas de acreditación y en diferentes instituciones con el fin de validar su construcción. Posteriores investigaciones deberían evaluar empíricamente la propuesta metodología y su aceptación como herramienta de apoyo procesos de calidad.

Para futuros estudios se destaca la necesidad de investigar cómo integrar los procesos de gestión de riesgos en el resto de los procesos académicos de una universidad con miras al mejoramiento de la calidad de la universidad como un todo.

\section{REFERENCIAS}

Albanese, D., Análisis y evaluación de riesgos: Aplicación de una matriz de riesgo en el marco de un plan de prevención contra el lavado de activos, BASE - Revista de Administração e Contabilidade da Unisinos, 9 (3), $206-215$ (2012)

Atehortua, F., R. Bustamante y J. Valencia, Sistema de gestión integral. Una sola gestión, un solo equipo, Medellín, Universidad de Antioquia (2008)

Aven, T., The risk concept-historical and recent development trends, Reliability Engineering y System Safety, 99, 33-44 (2012)

Brewer, A. e I. Walker, Risk management in a university environment, Journal of business continuity \& emergency planning, 5(2), 161-172 (2011)

Cassidy, D., L. Goldstein y otros tres autores, Developing a strategy to manage enterprise wide risk in higher education. Technical report, National Association of College and University Business Officers (NACUBO) and PricewaterhouseCoopers (2001)

Comisión Nacional de Acreditación, Reglamento sobre áreas de acreditación, Santiago de Chile (2013)

Delfiner, M. y C. Pailhé, Técnicas cualitativas para la gestión del riesgo operacional, Argentina, BCRA (2008)

Espinoza, Ó. y L.E. González, Accreditation in higher education in Chile: results and consequences. Quality Assurance in Education, 21(1), 20-38 (2013)

Galarza, J. y A. Almuiñas, La gestión de los riesgos de planificación estratégica en las instituciones de educación superior, Revista Cubana de Educación Superior, (2), 45-53 (2015)

Gallego, L., A. Muñoz y E. Carmona, El Dashboard Digital del Docente, Colombia, ELIZCOM S.A.S (2008)

Gómez, M., Introducción a la metodología de investigación científica, Córdoba, Brujas (2006)

Gustafson, P., Modeling the Security Risk Management Process in Higher Education Institutions to Understand, Explain and Improve, International Conference on Applied Human Factors and Ergonomics (2017)

Hope, J., y S. Player, Mejores prácticas de gestión empresarial: Cómo optimizar el control de la gestión, el rendimiento y los costes, Barcelona, Profit Editorial (2012)

Hurtado, F., Dirección de Proyectos: Una Introducción con base en el marco del PMI, USA, Palibrio (2011)

INN, Instituto Nacional de Normalización, Norma Chilena NCh-ISO 31000: Gestion del riesgo - Principios y orientaciones, Santiago de Chile (2012)

INN, Instituto Nacional de Normalización, Norma Chilena NCh-ISO 31010: Gestión del riesgo - Técnicas de evaluación del riesgo, Santiago de Chile (2013)

ISOTools, Norma ISO 31000: El valor de la gestión de riesgos en las organizaciones (I. E. Team, Ed.) (2015)

Lalonde, C. y O. Boiral, Managing risks through ISO 31000: A critical analysis. Risk management, 14(4), 272-300 (2012)

Larrán, M., J. Herrera y otros dos autores, A proposal for measuring sustainability in universities: a case study of Spain, International Journal of Sustainability in Higher Education, 17(5), 671-697 (2016)

Lumino, R., D. Gambardella y E. Grimaldi, The evaluation turn in the higher education system: lessons from Italy, Journal of Educational Administration and History, 49(2), 87-107 (2017)

Lundquist, A., Lessons from the Academy: ERM Implementation in University Settings, Academic Library (2015) 
Luko, S.N., Risk management principles and guidelines, Quality Engineering, 25(4), 451-454 (2013)

Mitroff, I.I., M.A. Diamond y M.C. Alpaslan, How prepared are America's colleges and universities for major crises? Change: The Magazine of Higher Learning, 38(1), 61-67 (2006)

Mukhtarova, A. y A. Smith, A., Aspiring International Standards: challenges and outcomes of project management in the context of Kazakhstan Higher Education, Life Science Journal, 11(6), 218-222 (2014)

Nava, V., ¿Qué es la calidad? Conceptos, gurús y modelos fundmentales, México, Limusa (2005)

Olechowski, A., J. Oehmen, W. Seering y M. Ben-Daya, The professionalization of risk management: What role can the ISO 31000 risk management principles play? International Journal of Project Management, 34(8), 1568-1578 (2016)

Ormella, C., Norma ISO 31000 de riesgos corporativos. Argentina. Recuperado el 5 de Mayo del 2016 (22 de Abril de 2014) Tlapa, D. A., Limón, J. y Báez, Y. A., Gestión de la Calidad y del Medio Ambiente en Instituciones de Educación Superior mediante Integración de ISO 9001 e ISO 14001, Formación Universitaria, 2(2), 35-46 (2009)

Tünnermann, C., La calidad de la educación superior y su acreditación: la experiencia centroamericana. Avaliação: Revista da Avaliação da Educação Superior (Campinas), 13(2), 313-336 (2008) 
